\title{
Extraction of dietary fibers from cassava pulp and cassava distiller's dried grains and assessment of their components using Fourier transform infrared spectroscopy to determine their further use as a functional feed in animal diets
}

\author{
Supattra Okrathok ${ }^{1}$, Kanjana Thumanu ${ }^{2}$, Chayanan Pukkung ${ }^{1}$, Wittawat Molee ${ }^{1}$, and Sutisa Khempaka ${ }^{1, *}$
}

\author{
* Corresponding Author: Sutisa Khempaka \\ Tel: +66-44224378, Fax: +66-44224376 \\ E-mail: khampaka@sut.ac.th \\ 'School of Animal Technology and Innovation, \\ Institute of Agricultural Technology, \\ Suranaree University of Technology, Nakhon \\ Ratchasima 30000, Thailand \\ 2 Synchrotron Light Research Institute (Public \\ Organization), Nakhon Ratchasima, 30000, \\ Thailand \\ ORCID \\ Supattra Okrathok \\ https://orcid.org/0000-0002-5233-5158 \\ Kanjana Thumanu \\ https://orcid.org/0000-0002-5815-7954 \\ Chayanan Pukkung \\ https://orcid.org/0000-0002-9867-645X \\ Wittawat Molee \\ https://orcid.org/0000-0003-2346-2980 \\ Sutisa Khempaka \\ https://orcid.org/0000-0003-1528-4109
}

Submitted Sept 20, 2021; Revised Nov 4, 2021; Accepted Dec 12, 2021
Objective: The present study was to investigate the extraction conditions of dietary fiber from dried cassava pulp (DCP) and cassava distiller's dried grains (CDG) under different $\mathrm{NaOH}$ concentrations, and the Fourier transform infrared (FTIR) was used to determine the dietary fiber components.

Methods: The dried samples (DCP and CDG) were treated with various concentrations of $\mathrm{NaOH}$ at levels of $2 \%, 4 \%, 6 \%$, and $8 \%$ using a completely randomized design with 4 replications of each. After extraction, the residual DCP and CDG dietary fiber were dried in a hot air oven at $55^{\circ} \mathrm{C}$ to $60^{\circ} \mathrm{C}$. Finally, the oven dried extracted dietary fiber was powdered to a particle size of $1 \mathrm{~mm}$. Both extracted dietary fibers were analyzed for their chemical composition and determined by FTIR.

Results: The DCP and CDG treated with $\mathrm{NaOH}$ linearly or quadratically or cubically ( $\mathrm{p}<$ 0.05 ) increased the total dietary fiber (TDF) and insoluble fiber (IDF). The optimal conditions for extracting dietary fiber from DCP and CDG were under treatment with $6 \%$ and $4 \%$ $\mathrm{NaOH}$, respectively, as these conditions yielded the highest TDF and IDF contents. These results were associated with the FTIR spectra integration for a semi-quantitative analysis, which obtained the highest cellulose content in dietary fiber extracted from DCP and CDG with $6 \%$ and $4 \% \mathrm{NaOH}$ solution, respectively. The principal component analysis illustrated clear separation of spectral distribution in cassava pulp extracted dietary fiber (DFCP) and cassava distiller's dried grains extracted dietary fiber (DFCDG) when treated with $6 \%$ and $4 \% \mathrm{NaOH}$, respectively.

Conclusion: The optimal conditions for the extraction of dietary fiber from DCP and CDG were treatment with $6 \%$ and $4 \% \mathrm{NaOH}$ solution, respectively. In addition, FTIR spectroscopy proved itself to be a powerful tool for fiber identification.

Keywords: Cassava Distiller's Dried Grains; Cassava Pulp; Dietary Fiber; Fourier Transform Infrared Spectroscopy

\section{INTRODUCTION}

Dietary fiber is defined as non-starch polysaccharides (NSPs) that cannot be digested by enzymes in the gastrointestinal tract of poultry. These polysaccharides can be found naturally in feedstuffs include cellulose, non-cellulosic polysaccharides such as hemicellulose, pectic substances, gums, mucilage, and a non-carbohydrate component lignin [1,2]. Dietary fiber is classified into water soluble dietary fiber (SDF) and insoluble dietary fiber (IDF), the content and composition of SDF and IDF vary with feedstuff type. Dietary fiber plays an important role in poultry physiology. Its effects depend on structures and physicochemical properties. In particular, IDF has been shown to improve gut health, litter and 
nutrient utilization, by increasing crop and gizzard activity, stimulating digestive enzyme production and enhancing bacterial fermentation in the hind gut [3]. Additionally, dietary fiber can improve the intestinal microbial balance when the fibers are fermented by resident anaerobic microflora and produce short chain fatty acids. These end products can lower the intestinal $\mathrm{pH}$ and in the long term would lead to a reduction in the population of pathogenic bacteria. Such effects promote the gut health and function positively on improving growth performance, including mitigate $\mathrm{NH}_{3}$ emission in excreta of poultry [4]. Therefore, alternative dietary fiber sources derived from agro-industrial by-products could be a useful feed to improve animal health and provide the benefits of good waste management.

Cassava by-products in the form of dried cassava pulp (DCP) and cassava distiller's dried grains (CDG) are annually generated in large amounts (approximately 2 to 3 and 0.74 to 0.95 million tons per year) from starch factories and by the bioethanol production process in Thailand, respectively. These by-products contain high NSPs which are mainly composed of cellulose, hemicellulose, and lignin $[5,6]$. The fiber extracted from DCP and CDG can be further used in poultry diets as it provides health benefits and productive performance as well as good waste management. Previous studies reported several methods of extracting dietary fiber, unfortunately, there is little information available on the extraction of cassava by-products. A combination of enzymatic and solvent methods is usually used for dietary fiber extraction. For example, starch and protein are first removed by amylase and protease or a suitable solvent (such as a neutral, alkaline, acidic detergent). The different fiber extraction conditions affect the properties of dietary fiber in both composition and structure [7]. Daou and Zhang [8] reported that the extraction of dietary fiber from defatted rice bran and the alkaline pretreatment with $\mathrm{NaOH}$ were the factors amongst others (e.g. concentration and soaking time) which significantly affected the purity of fiber fractions. Samanta et al [9] stated that the alkaline extraction ( $\mathrm{NaOH}$ solution) can yield xylan in agricultural by-products. Crude fiber assay is still being used today as the legal measure of fiber in grains and finished feeds of non-ruminant animals. However, it is not a good indicator because some parts of the fiber can ferment in the large intestine or caecum. Thus, the true fiber contents have attracted more interest because of the potential improvements in the accuracy of future measurements [1]. A power tool to identify the components in fiber could offer a rapid and reliable alternative technique.

Fourier transform infrared (FTIR) Spectroscopy has become an attractive alternative to traditional methods since it is a rapid analytical technique which uses non-destructive samples and minimizes hazardous chemical use. The FTIR can provide information regarding the functional groups, chemical bonds, composition, structure, and quality of a product. Infrared (IR) spectra combined with chemometric techniques, such as principal component analysis (PCA), can be used to obtain accurate dietary fiber components [1012]. FTIR Spectroscopy has been used to study the relationship of feed intrinsic structures pertaining to protein molecular structures, carbohydrates, and starch matrices [10], quantitative analysis of tapioca starch [13], and polysaccharide food additives [14]. It can be used to analyze the chemical composition of cell walls, the structure of natural fiber and fiber composition [15]. The application of FTIR to identify the fractions of dietary fiber from DCP and CDG would be a useful tool for the assessment of dietary fiber components.

The present study primarily focused on the investigation of the extraction conditions of dietary fiber from DCP and CDG by using different $\mathrm{NaOH}$ concentrations, with the purpose of producing dietary fiber. To the best of our knowledge, this is the only study of dietary fiber estimation using FTIR analysis to determine dietary fiber components combined with multivariate data analysis using PCA.

\section{MATERIALS AND METHODS}

\section{Sample preparation}

Fresh cassava pulp was obtained from the Korat Flour Industry Co., Ltd, Nakhon Ratchasima, Thailand. Fresh CDGs were obtained from the Thai ethanol power Pub Co., Ltd, Khon Kaen, Thailand. These were dried in a hot air oven at $55^{\circ} \mathrm{C}$ to $60^{\circ} \mathrm{C}$ for $2 \mathrm{~d}$ and then were ground to pass through a $1.0 \mathrm{~mm}$ mesh sieve before being stored at $4^{\circ} \mathrm{C}$ until further use. Prior to extraction, DCP and CDG were analyzed for dry matter, crude protein, ash, and ether extract according to the standard methods of AOAC [16]. The contents of total soluble and IDF were determined using the total dietary fiber Kit (K-TDFR-100A, Megazyme International Ltd., Wicklow, Ireland). Briefly, the samples $(1 \mathrm{~g})$ were treated with thermostable $\alpha$-amylase and then incubated at $60^{\circ} \mathrm{C}$ with protease and amyloglucosidase to eliminate starch and protein components. The IDF was obtained by filtration and the residue was washed with warm distilled water. The SDF was precipitated with $95 \%$ ethanol and filtered. Total dietary fiber (TDF) was calculated as the sum of SDF and IDF. The chemical compositions of DCP and CDG are shown in Table 1.

\section{Experimental design and dietary fiber extraction}

Dietary fiber from DCP and CDG were treated with various concentrations of $\mathrm{NaOH}$ at levels of $2 \%, 4 \%, 6 \%$, and $8 \%$ using a completely randomized design with 4 replications of each. The extraction procedure was slightly modified from Daou and Zhang [8]. A dried sample (1.0 g) was pretreated with $5.0 \mathrm{~mL} \mathrm{NaOH}$ solution at different concentrations $(2 \%, 4 \%$, 
Table 1. The chemical compositions of dried cassava by-products

\begin{tabular}{lcc}
\hline Compositions (\%) & Cassava pulp & $\begin{array}{c}\text { Cassava distiller's } \\
\text { dried grains }\end{array}$ \\
\hline Dry matter & 93.79 & 92.26 \\
Crude protein & 2.30 & 10.14 \\
Ash & 1.87 & 16.58 \\
Ether extract & 0.22 & 1.02 \\
Total dietary fiber & 17.36 & 21.47 \\
Soluble dietary fiber & 2.29 & 3.09 \\
Insoluble dietary fiber & 15.07 & 18.38 \\
\hline
\end{tabular}

$6 \%$, and $8 \%$ ), the mixture was soaked for $1 \mathrm{~h}$ at room temperature, then centrifuged, and the residue was washed to $\mathrm{pH} 7.0$ with distilled water. The sample was suspended in phosphate buffer ( $\mathrm{pH}$ 6.0) ratio 1:30, and $\alpha$-amylase (EC 3.2.1.1, Megazyme, Ireland) was added, then the mixture was incubated at $95^{\circ} \mathrm{C}$ in a boiling water bath for $1 \mathrm{~h}$. The sample was allowed to cool at room temperature. The dietary fiber was precipitated in $95 \%$ ethanol at $60^{\circ} \mathrm{C}$ for $1 \mathrm{~h}$, then was cooled to room temperature, and centrifuged. After centrifugation, the residue was washed with $78 \%$ ethanol, $95 \%$ ethanol and acetone, respectively, and finally dried at $55^{\circ} \mathrm{C}$ to $60^{\circ} \mathrm{C}$ overnight.

\section{Analysis of dietary fiber content}

The DFCP and the DFCDG were analyzed to determine the amounts of TDF, SDF, and IDF by using a total dietary fiber Kit (K-TDFR-100A, Megazyme International Ltd., Ireland), according to the manufacturer's instructions.

\section{Fourier transform infrared spectroscopy}

The infrared spectra were collected using attenuated total reflectance (ATR)-FTIR spectroscopy with single reflection ATR sampling module and coupled with a DTGS detector over the measurement range from 4,000 to $400 \mathrm{~cm}^{-1}$. The measurements were performed with a spectral resolution of $4 \mathrm{~cm}^{-1}$ with 64 scans co-added (Bruker Optics Ltd, Ettlingen,
Germany). OPUS software was used for data acquisition and the spectra evaluation. The spectral changes of the functional groups were performed at the integral area of each peak such as cellulose, hemicellulose, lignin, and starch by using OPUS software.

\section{Principal component analysis}

The FTIR spectra were exported to the Unscrambler X 10.5 (CAMO, Oslo, Norway) for using PCA analysis. The spectral data were preprocessed by taking the 2 nd derivative with Savitzky-Golay method (3rd polynomial, 9 smoothing points), normalization with extended multiplicative signal correction and PCA were performed for the determination of a significant variation between the spectra sets. In this study, PCA was used to compare the FTIR spectra of dietary fiber sources under treatment with different conditions of $\mathrm{NaOH}$ solution $(2 \%, 4 \%, 6 \%$, and $8 \%)$. The output of PCA can be presented as the sources of variability of data which were concentrated into the principal component (PC). The spectra were processed using the second derivative and vector normalized by the Savitzky-Golay method, and using the third polynomial and nine smoothing points setting [17].

\section{Statistical analysis}

The experimental design was completely randomized design. Determinations for analysis were made using a total of 4 replicates. Statistical analyses of dietary fiber contents (TDF, SDF, and IDF) and peak area proportions from integrating FTIR spectra were performed using SPSS software version 18.0 [18]. Data were analyzed using one-way analysis of variance followed by Tukey's tests. Orthogonal polynomials were also used to assess linear, quadratic, and cubic effects of $\mathrm{NaOH}$ levels. Values were statistically different at $\mathrm{p}<0.05$.

\section{RESULTS AND DISCUSSION}

\section{The components of dietary fiber extracted from dried}

Table 2. The contents of total, soluble and insoluble dietary fiber from cassava pulp extracted dietary fiber and cassava distiller's dried grains extracted dietary fiber

\begin{tabular}{|c|c|c|c|c|c|c|c|c|c|}
\hline \multirow{2}{*}{ Item } & \multicolumn{4}{|c|}{ Concentration of $\mathrm{NaOH}$ levels } & \multirow{2}{*}{ SEM } & \multicolumn{4}{|c|}{ p-values } \\
\hline & $2 \%$ & $4 \%$ & $6 \%$ & $8 \%$ & & ANOVA & Linear $^{1)}$ & Quadratic $^{1)}$ & Cubic $^{1)}$ \\
\hline \multicolumn{10}{|c|}{ Cassava pulp extracted dietary fiber } \\
\hline Total dietary fiber & $23.60^{b}$ & $24.29^{b}$ & $27.93^{\mathrm{a}}$ & $27.60^{a}$ & 0.57 & 0.001 & 0.001 & 0.285 & 0.032 \\
\hline Soluble dietary fiber & 3.65 & 2.57 & 3.19 & 2.84 & 0.19 & 0.501 & 0.501 & 0.188 & 0.365 \\
\hline Insoluble dietary fiber & $19.95^{b}$ & $21.72^{a b}$ & $24.73^{\mathrm{a}}$ & $24.76^{a}$ & 0.63 & 0.001 & 0.001 & 0.117 & 0.089 \\
\hline \multicolumn{10}{|c|}{ Cassava distiller's dried grains extracted dietary fiber } \\
\hline Total dietary fiber & $22.85^{\mathrm{b}}$ & $25.12^{\mathrm{a}}$ & $25.33^{\mathrm{a}}$ & $25.35^{\mathrm{a}}$ & 0.30 & $<0.001$ & $<0.001$ & $<0.001$ & 0.009 \\
\hline Soluble dietary fiber & 2.38 & 2.59 & 2.33 & 2.32 & 0.06 & 0.313 & 0.368 & 0.356 & 0.152 \\
\hline Insoluble dietary fiber & $20.46^{\mathrm{b}}$ & $22.53^{\mathrm{a}}$ & $23.00^{\mathrm{a}}$ & $23.03^{a}$ & 0.31 & $<0.001$ & $<0.001$ & $<0.001$ & 0.186 \\
\hline
\end{tabular}

SEM, standard error of the means; ANOVA, analysis of variance.

1) Orthogonal polynomials were used to evaluate linear, quadratic, and cubic responses to the concentration of $\mathrm{NaOH}$ levels.

$a, b$ Means with different superscripts in a row are significantly different $(p<0.05)$ 
cassava pulp and cassava distiller's dried grains The DCP and CDG were treated with different concentrations of $\mathrm{NaOH}$ solution $(2 \%, 4 \%, 6 \%$, and $8 \%)$ to determine the optimal conditions for dietary fiber extraction. The contents of TDF, SDF, and IDF after extraction are shown in Table 2. The DFCP consisted of an increase in TDF (cubic, $p$ $=0.032$ ) and IDF (linear, $p=0.001$ ) in response to increased $\mathrm{NaOH}$ levels. It revealed that DFCP derived from treated DCP with $\mathrm{NaOH}$ at concentrations of $6 \%$ and $8 \%$ produced significantly greater amounts of TDF and IDF than $2 \% \mathrm{NaOH}$ $(\mathrm{p}<0.05)$. In addition, the DFCDG also comprised an increase in TDF (cubic, $p=0.009$ ) and IDF (quadratic, $p<0.001$ ). The DFCDG obtained by treatment CDG with $4 \%, 6 \%$, and $8 \%$ $\mathrm{NaOH}$ produced higher contents of TDF and IDF than $2 \%$ $\mathrm{NaOH}(\mathrm{p}<0.05)$. However, the SDF content in both DFCP and DFCDG showed no significant differences $(p>0.05)$ between treatments.

This study showed that the optimum levels of $\mathrm{NaOH}$ for the extraction of dietary fiber from DCP and CDG were 6\% to $8 \%$ and $4 \%$ to $8 \%$, respectively. The IDF represented a major component in both dietary fiber sources. In general, some hemicellulose such as $\beta$-glucans, pectin, and gums are defined as SDF, whilst cellulose and lignin are defined as IDF $[1,19]$. Cellulose is the main structural constituent in plant cell walls, and also in cassava by-products $[1,5,6]$. Previous studies have shown that defatted rice bran treated with $0.6 \% \mathrm{NaOH}$ solution can produce the maximum yield and purity of TDF, SDF, and IDF [8]. Samanta et al [9] demonstrate that the extraction agricultural by-products with $\mathrm{NaOH}$ solution resulted in recovery of more than $90 \%$ of original xylan in plant materials. The results were similar to the highest xylan recovery from sugarcane bagasse [20]. Harun and Geok [21] stated that rice straw treated with $\mathrm{NaOH}$ obtained the highest glucan and lower lignin composition.

\section{FTIR Spectra of dietary fiber extracted from dried cassava pulp and cassava distiller's dried grains} The band assignment of FTIR spectra of isolated dietary fiber is shown in Table 3. The spectral features of DFCP and DFCDG are shown in Figures 1 and 2. In this study, FTIR spectra were used to detect the extracted dietary fiber treated with $\mathrm{NaOH}$ solution in the spectral region of 4,000 to $400 \mathrm{~cm}^{-1}$. A total of 428 and 434 FTIR spectra of DFCP and DFCDG were analyzed. The fingerprint regions of specific interest in this study were between 1,700 and $800 \mathrm{~cm}^{-1}$, although many absorption bands associated with various $\mathrm{NaOH}$ solutions from vibrational modes in the wavelength region are also present in DFCP and DFCDG. The FTIR spectra measurements were carried out to reveal the molecular characteristics of functional groups of dietary fiber such as cellulose, hemicellulose and lignin. This technique can give information about the functional groups of $\mathrm{C}-\mathrm{O}, \mathrm{C}-\mathrm{O}-\mathrm{C}$ glycoside, and $\mathrm{C}-\mathrm{C}$ from cellulose, hemicellulose, lignin, starch, and glucose in extracted dietary fiber [22-24].

The semi-quantitative analysis of FTIR spectra was carried out by using OPUS software. The presented FTIR spectra were used to average the single spectra of each sample. The wavenumber of the FTIR spectra was determined to be in the region of 3,500 to $800 \mathrm{~cm}^{-1}$ for the peak area integration, and the total area of integrated peaks was defined as $100 \%$. The peak area units were expressed as relative proportions of the components in DFCP and DFCDG. The results of the

Table 3. Infrared assignment of the main bands in Fourier transform infrared spectra

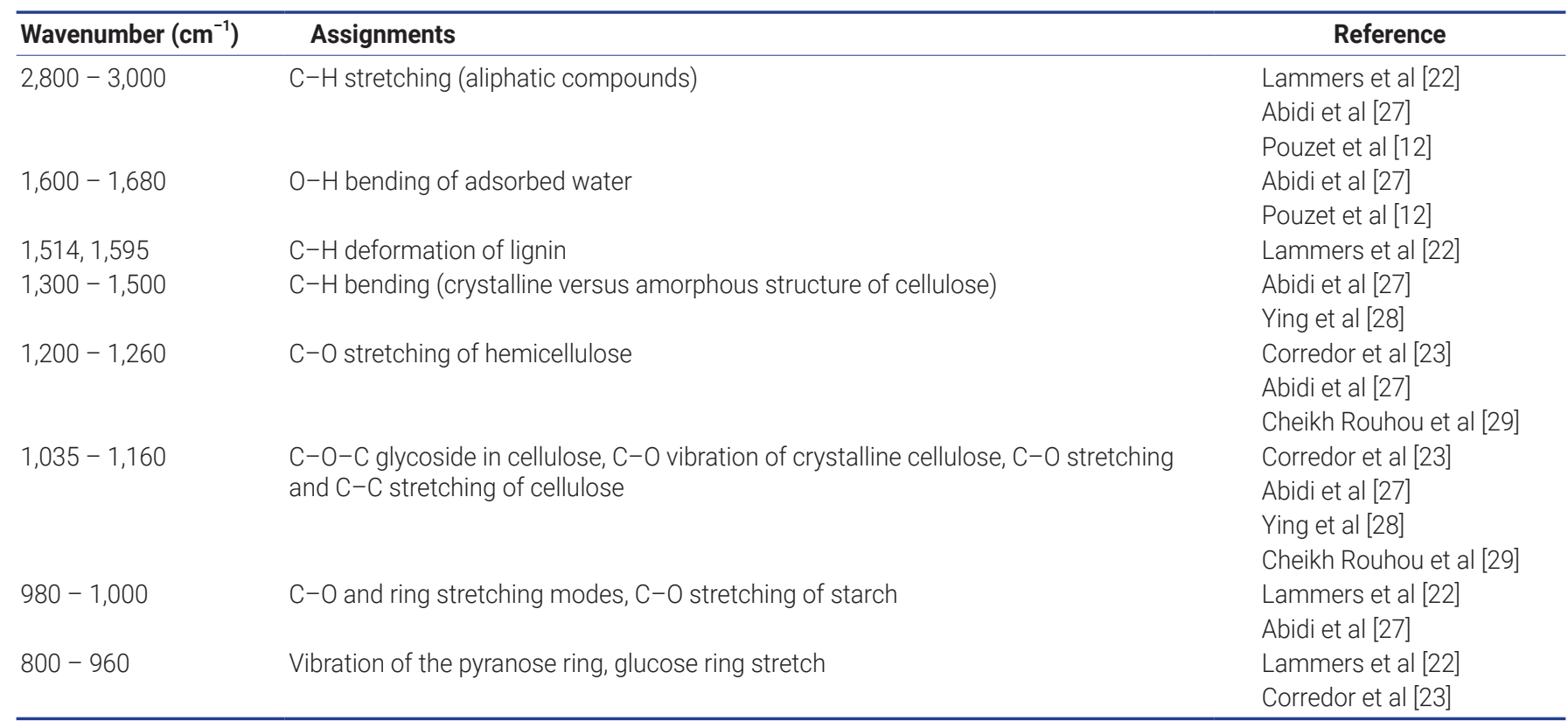


(A)
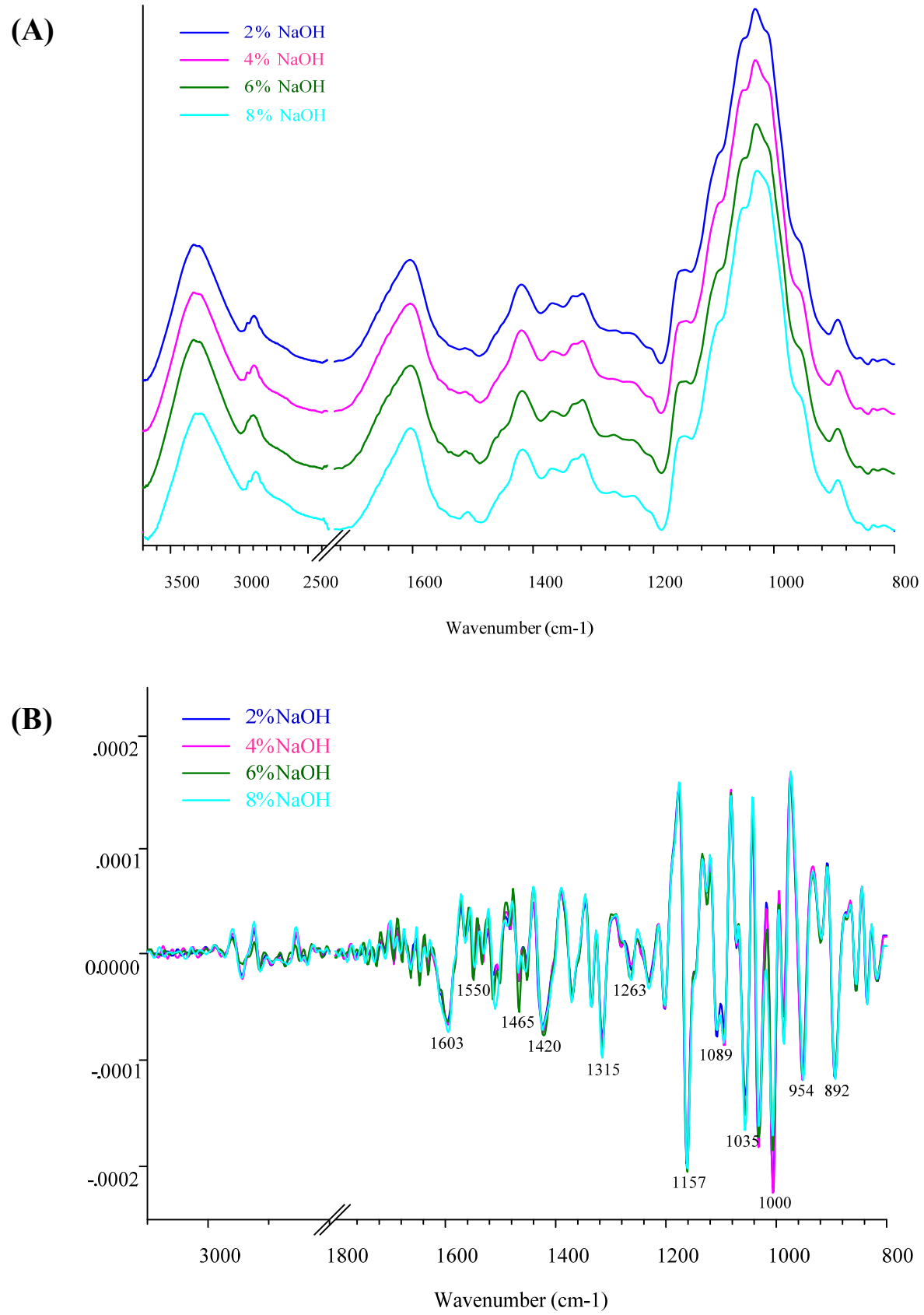

Figure 1. Fourier transform infrared (FTIR) spectra of cassava pulp extracted dietary fiber (DFCP) treated with $\mathrm{NaOH}$ solution at concentrations $2 \%, 4 \%, 6 \%$, and $8 \%$, (A) Average original FTIR spectra of DFCP, (B) The 2nd derivative spectra of DFCP. The infrared (IR) spectra detected in spectra region from 4,000 to $400 \mathrm{~cm}^{-1}$, resolution $4 \mathrm{~cm}^{-1}$, with 64 scans.

semi-quantitative analysis of DFCP and DFCDG using FTIR spectra in term of proportions (\%) of the functional groups are presented in Table 4 . The results showed that DFCP comprised of an increase in $\mathrm{C}-\mathrm{H}$ bending of crystalline versus amorphous structure of cellulose (cubic, $\mathrm{p}<0.001$ ), $\mathrm{C}-\mathrm{O}$ stretching of hemicellulose (cubic, $\mathrm{p}=0.001$ ) and $\mathrm{C}-\mathrm{O}-\mathrm{C}$ glycoside, $\mathrm{C}-\mathrm{O}$ and $\mathrm{C}-\mathrm{C}$ stretching of cellulose (cubic, $\mathrm{p}=$ 0.029 ) in response to increased $\mathrm{NaOH}$ levels. The DFCP derived from treated $\mathrm{DCP}$ with $6 \% \mathrm{NaOH}$ yielded significant proportions of $\mathrm{C}-\mathrm{H}$ bending of crystalline cellulose and $\mathrm{C}-\mathrm{O}-$ $\mathrm{C}$ glycoside, $\mathrm{C}-\mathrm{O}$ and $\mathrm{C}-\mathrm{C}$ stretching of cellulose compared to $2 \%$ and $4 \% \mathrm{NaOH}(\mathrm{p}<0.05)$, but there was no significant difference when compared to $8 \% \mathrm{NaOH}$ treatment. While the proportions of the components in DFCDG with peak area integration revealed an increase in $\mathrm{C}-\mathrm{H}$ stretching (linear, $\mathrm{p}=0.002$ ), $\mathrm{C}-\mathrm{H}$ bending of crystalline cellulose (linear, $\mathrm{p}=0.015$ ), $\mathrm{C}-\mathrm{O}-\mathrm{C}$ glycoside, $\mathrm{C}-\mathrm{O}$ and $\mathrm{C}-\mathrm{C}$ stretching of cellulose (cubic, $\mathrm{p}=0.033$ ), $\mathrm{C}-\mathrm{O}$ stretching of starch 


\section{(A)}

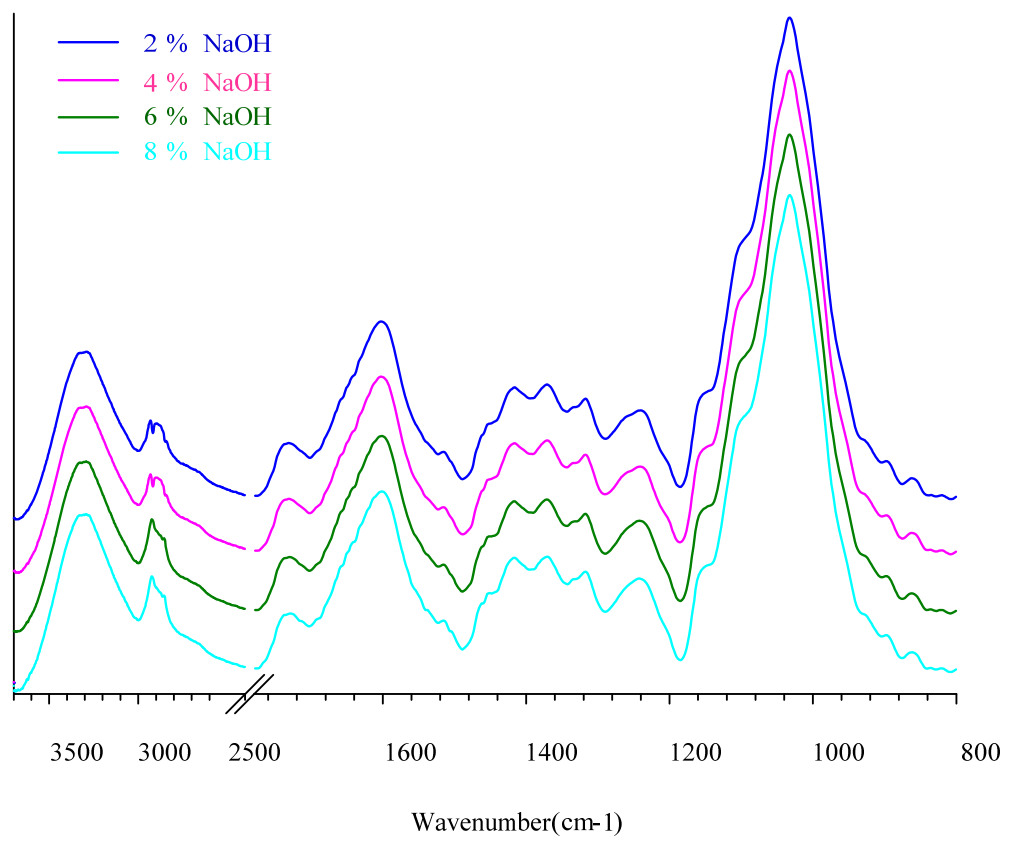

(B)

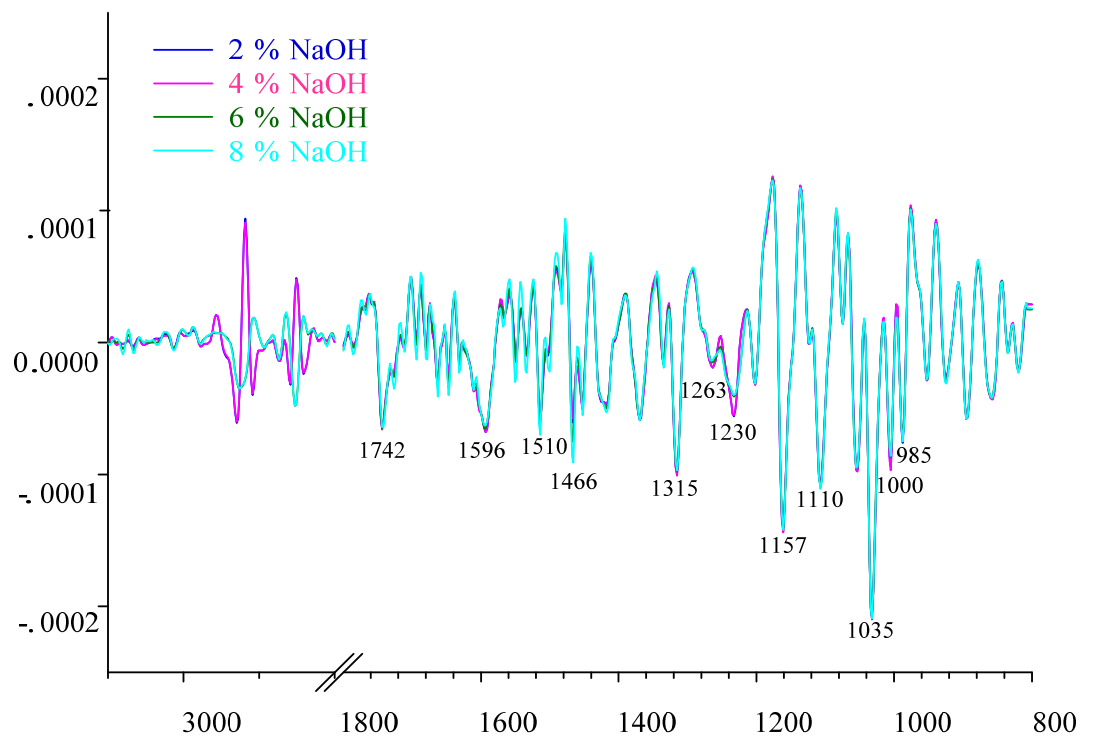

Wavenumber(cm-1)

Figure 2. Fourier transform infrared (FTIR) spectra of cassava distiller's dried grains extracted dietary fiber (DFCDG) treated with NaOH solution at concentrations $2 \%, 4 \%, 6 \%$, and $8 \%$, (A) Average original FTIR spectra of DFCDG, (B) The 2 nd derivative spectra of DFCDG. The IR spectra detected in spectra region from 4,000 to $400 \mathrm{~cm}^{-1}$, resolution $4 \mathrm{~cm}^{-1}$, with 64 scans.

(linear, $\mathrm{p}<0.001$ ) and vibration of the pyranose ring (quadratic, $\mathrm{p}=0.004)$. The DFCDG derived from treated CDG with $4 \% \mathrm{NaOH}$ resulted in a significant yield of $\mathrm{C}-\mathrm{O}-\mathrm{C}$ glycoside, $\mathrm{C}-\mathrm{O}$ and $\mathrm{C}-\mathrm{C}$ stretching of cellulose compared to $2 \% \mathrm{NaOH}(\mathrm{p}<0.05)$. However, no significant differences were observed in crystalline structure of cellulose in response to the concentration of $2 \%$ and $4 \% \mathrm{NaOH}$. These results were similar to the chemical composition of DCP treated with $6 \% \mathrm{NaOH}$ and $\mathrm{CDG}$ treated with $4 \% \mathrm{NaOH}$, which showed higher functional groups of cellulose. It has been well-established previously that IDF commonly includes cellulose [7].

\section{PCA analysis and extracted dietary fiber components} In this study, the DCP and CDG treated with $\mathrm{NaOH}$ solutions at a concentration of $2 \%, 4 \%, 6 \%$, and $8 \%$ were identified by their spectral distribution by using PCA. The PCA scores were plotted to characterize the sample relationships between 
Table 4. The integral area from Fourier transform infrared spectra of extracted dietary fiber

\begin{tabular}{|c|c|c|c|c|c|c|c|c|c|}
\hline \multirow{2}{*}{ Item } & \multicolumn{4}{|c|}{ Concentration of $\mathrm{NaOH}$ levels } & \multirow{2}{*}{ SEM } & \multicolumn{4}{|c|}{ p-values } \\
\hline & $2 \%$ & $4 \%$ & $6 \%$ & $8 \%$ & & ANOVA & Linear $^{1)}$ & Quadratic $^{1)}$ & Cubic $^{1)}$ \\
\hline \multicolumn{10}{|l|}{ Cassava pulp extracted dietary fiber } \\
\hline $\mathrm{O}-\mathrm{H}$ bending of adsorbed water & 8.86 & 8.87 & 7.79 & 8.52 & 0.17 & 0.065 & 0.116 & 0.237 & 0.052 \\
\hline $\mathrm{C}-\mathrm{H}$ deformation of lignin & 0.66 & 0.79 & 0.75 & 0.73 & 0.04 & 0.612 & 0.595 & 0.272 & 0.574 \\
\hline $\mathrm{C}-\mathrm{H}$ bending of crystalline cellulose & $18.20^{\mathrm{bc}}$ & $17.06^{\mathrm{c}}$ & $19.54^{\mathrm{a}}$ & $18.57^{\mathrm{ab}}$ & 0.27 & 0.001 & 0.018 & 0.769 & $<0.001$ \\
\hline $\mathrm{C}-\mathrm{O}$ stretching of starch & 17.96 & 18.21 & 18.75 & 19.11 & 0.24 & 0.346 & 0.082 & 0.905 & 0.831 \\
\hline Vibration of the pyranose ring & 18.15 & 17.97 & 16.99 & 17.15 & 0.23 & 0.178 & 0.055 & 0.679 & 0.318 \\
\hline \multicolumn{10}{|c|}{ Cassava distiller's dried grains extracted dietary fiber } \\
\hline $\mathrm{C}-\mathrm{H}$ stretching & $3.56^{\mathrm{ab}}$ & $3.89^{\mathrm{a}}$ & $2.43^{\mathrm{bc}}$ & $2.10^{c}$ & 0.25 & 0.007 & 0.002 & 0.345 & 0.087 \\
\hline $\begin{array}{l}\mathrm{C}-\mathrm{O}-\mathrm{C} \text { glycoside, } \mathrm{C}-\mathrm{O} \text { and } \mathrm{C}-\mathrm{C} \\
\text { stretching of cellulose }\end{array}$ & $20.57^{b}$ & $22.58^{\mathrm{a}}$ & $21.95^{\mathrm{a}}$ & $22.28^{\mathrm{a}}$ & 0.26 & 0.004 & 0.008 & 0.024 & 0.033 \\
\hline $\mathrm{C}-\mathrm{O}$ stretching of starch & $22.67^{\circ}$ & $23.23^{\mathrm{bc}}$ & $24.36^{\mathrm{ab}}$ & $25.64^{\mathrm{a}}$ & 0.35 & 0.001 & $<0.001$ & 0.356 & 0.807 \\
\hline Vibration of the pyranose ring & $10.03^{b}$ & $9.44^{b}$ & $9.94^{\mathrm{b}}$ & $10.98^{\mathrm{a}}$ & 0.18 & 0.003 & 0.005 & 0.004 & 0.593 \\
\hline
\end{tabular}

SEM, standard error of the means; ANOVA, analysis of variance.

1) Orthogonal polynomials were used to evaluate linear, quadratic, and cubic responses to the concentration of $\mathrm{NaOH}$ levels.

${ }^{a-c}$ Means with different superscripts in a row are significantly different $(p<0.05)$.

the spectra and the dietary fiber extraction treatments. The FTIR characterizes chemical structure by identifying the functional groups present in each sample.

The results of the PCA scores from DFCP are presented in Figures 3. The variability of PC-1 and PC-2 accounts for $58 \%$ and $13 \%$, respectively. The scores plot of DFCP derived from DCP treated with $6 \%$ and $8 \% \mathrm{NaOH}$ appear clearly in the negative PC- 1 score plot, while the scores plot of $2 \%$ and $4 \% \mathrm{NaOH}$ treatments are clearly separated in the positive PC-1 score plot. The highest negative loading plot in PC-1 was observed in the $\mathrm{C}-\mathrm{O}-\mathrm{C}$ stretch of cellulose (centered at $1,170 \mathrm{~cm}^{-1}$ ), C-O vibrations of cellulose (centered at 1,035 $\mathrm{cm}^{-1}$ ), C-O and ring stretching (centered at 1,000 and 985 $\mathrm{cm}^{-1}$ ), which was oppositely correlated with the positive score plots in DFCP treated with $2 \%$ and $4 \% \mathrm{NaOH}$ group from the second derivative spectrum. While the treatment using $6 \% \mathrm{NaOH}$ shows the scores plot differ from $8 \% \mathrm{NaOH}$ and almost appear on the positive side of PC-2. The positive loading plot in PC-2 reveals $\mathrm{O}-\mathrm{H}$ bending of adsorbed water (centered at 1,603 $\mathrm{cm}^{-1}$ ), C-H bending of crystalline cellulose (centered at $1,407 \mathrm{~cm}^{-1}$ ), $\mathrm{C}-\mathrm{O}$ and $\mathrm{C}-\mathrm{O}-\mathrm{C}$ stretching (centered at 1,089 and $1,016 \mathrm{~cm}^{-1}$ ), and $\mathrm{C}-\mathrm{O}$ stretching of starch (centered at $981 \mathrm{~cm}^{-1}$ ).

The score plot of the FTIR spectra of DFCDG is presented in Figures 4. The variation of spectra in PC-1 and PC-2 accounts for $30 \%$ and $23 \%$, respectively. The scores plot of DFCDG derived from CDG treated with $2 \%$ and $4 \% \mathrm{NaOH}$ appear in the negative PC-1 score plot, while the scores plot of $6 \%$ and $8 \% \mathrm{NaOH}$ appears separately in the positive $\mathrm{PC}-1$ score plot. The negative loading plot in $\mathrm{PC}-1$ reveals $\mathrm{C}-\mathrm{H}$ bending (centered at $1,472 \mathrm{~cm}^{-1}$ ), $\mathrm{C}-\mathrm{O}$ and ring stretching (centered at $1,000 \mathrm{~cm}^{-1}$ ), and vibrations of the pyranose ring, glucose ring stretch (centered at $954 \mathrm{~cm}^{-1}$ ). The DFCDG derived from $\mathrm{CDG}$ treated with $4 \% \mathrm{NaOH}$ show the scores plot differs from that of $2 \% \mathrm{NaOH}$ and almost appears in the positive PC-2 score plot. The positive loading plot in PC-2 reveals $\mathrm{O}-\mathrm{H}$ bending of adsorbed water (centered at 1,620 $\mathrm{cm}^{-1}$ ), $\mathrm{C}-\mathrm{H}$ bending of crystalline cellulose (centered at $\left.1,316 \mathrm{~cm}^{-1}\right)$, and $\mathrm{C}-\mathrm{O}$ stretching and $\mathrm{C}-\mathrm{C}$ stretching of cellulose (centered at 1,078 and $1,018 \mathrm{~cm}^{-1}$ ).

The results of DCP and CDG using different $\mathrm{NaOH}$ solutions indicate that PCA analysis of FTIR spectroscopy reveals differences in DCP and CDG treated with 6\% and CDG 4\% $\mathrm{NaOH}$ solutions, respectively. These results are related to the semi-quantitative analysis by integral area obtained from the spectra. The results also show the main components of cellulose in both dietary fiber sources. These results are consistent with those of Uthumporn et al [25], who found the predominant content of NSPs extracted from sago palm flour were cellulose, hemicellulose, pectin, and lignin by using FTIR. Chirinang et al [26] reported that the FTIR spectrum of dietary fiber from cassava pulp appears in the band of 1,031 to $1,005 \mathrm{~cm}^{-1}$. This band is the fingerprint of polysaccharides. These results show that FTIR spectroscopy can be used as a 
(A)

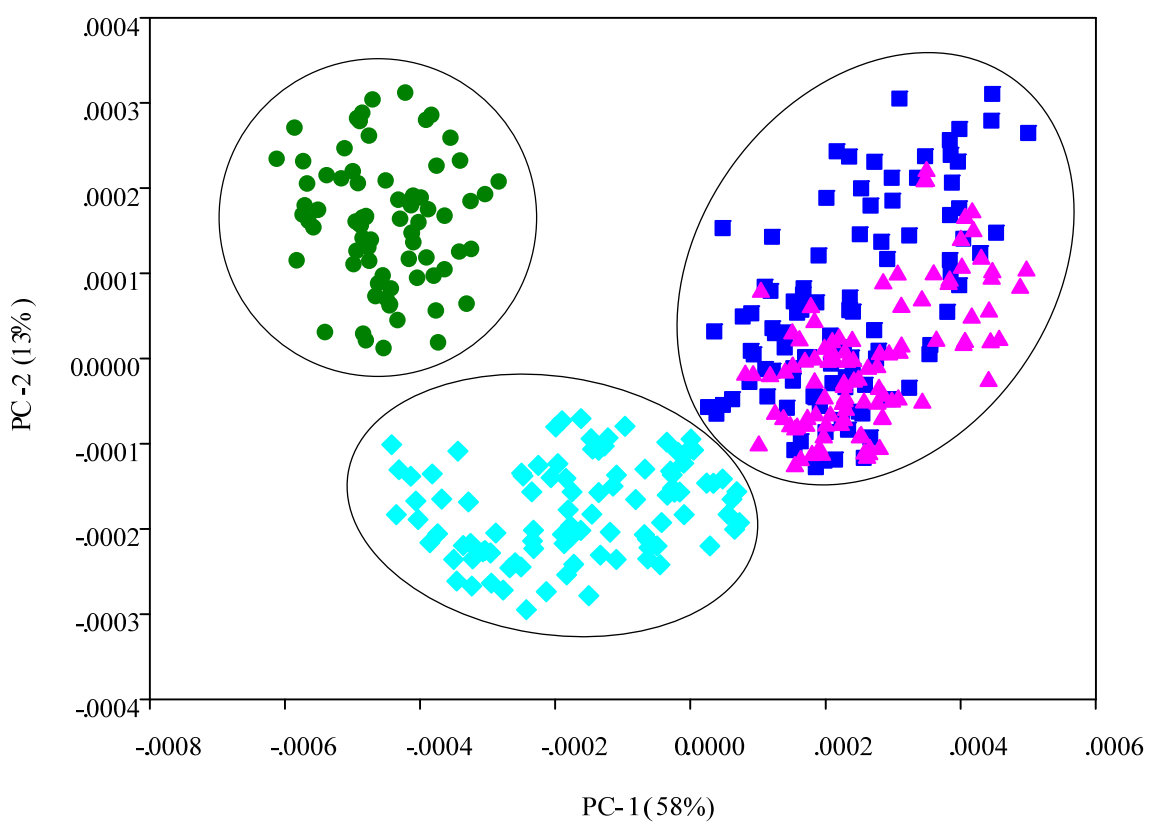

- $2 \% \mathrm{NaOH} \Delta 4 \% \mathrm{NaOH} \bullet 6 \% \mathrm{NaOH} \bullet 8 \% \mathrm{NaOH}$

(B)

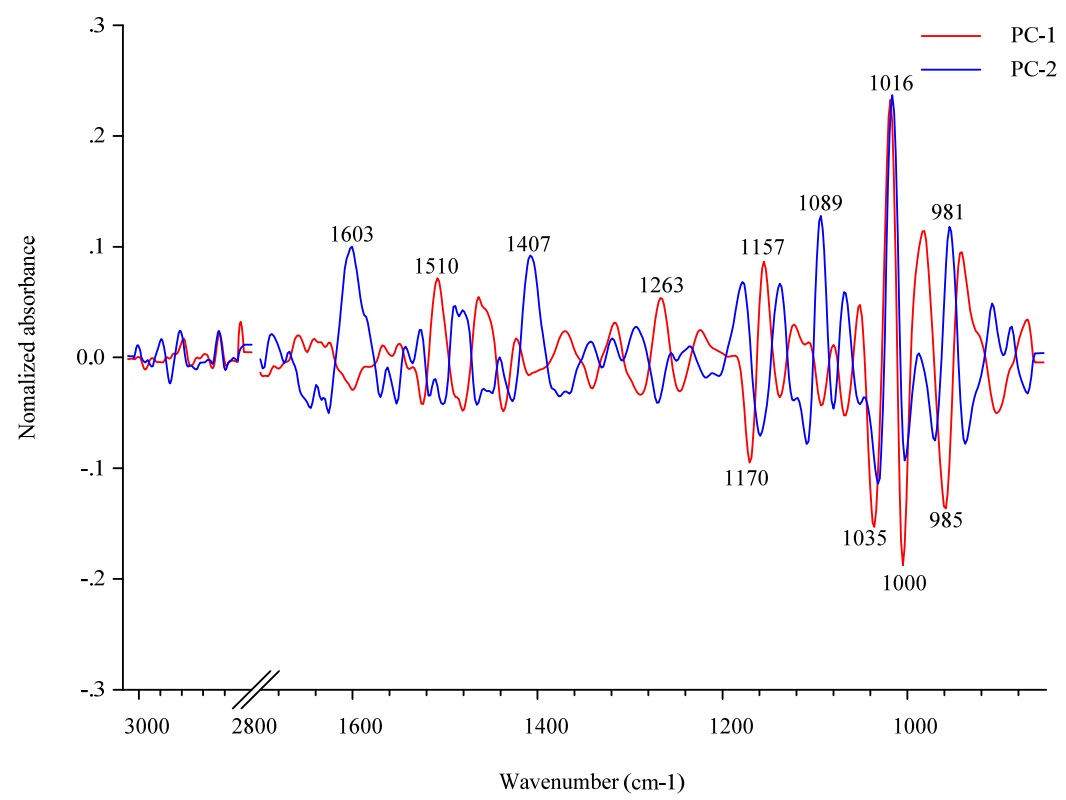

Figure 3. Principal component analysis (PCA) scores scatter plot of Fourier transform infrared (FTIR) spectra of cassava pulp extracted dietary fiber (DFCP) treated with $\mathrm{NaOH}$ solution at concentrations 2\%, 4\%,6\%, and 8\%, (A) PCA scores plot, (B) PCA loading plot.

very reliable and quick tool for evaluating and monitoring dietary fiber.

\section{CONCLUSION}

It was demonstrated that DCP and CDG treated with $6 \%$ and $4 \% \mathrm{NaOH}$ solutions respectively, obtained the highest TDF and IDF contents. These results are associated with the
FTIR spectra integration from a semi-quantitative analysis, which indicates the spectral distribution of dietary fiber components of DCP treated with $6 \% \mathrm{NaOH}$ and $\mathrm{CDG}$ treated with $4 \% \mathrm{NaOH}$ have a clearly separated spectral distribution. This study reveals that FTIR spectroscopy is a useful and rapid technique for fiber identification and the semiquantitative analysis. 


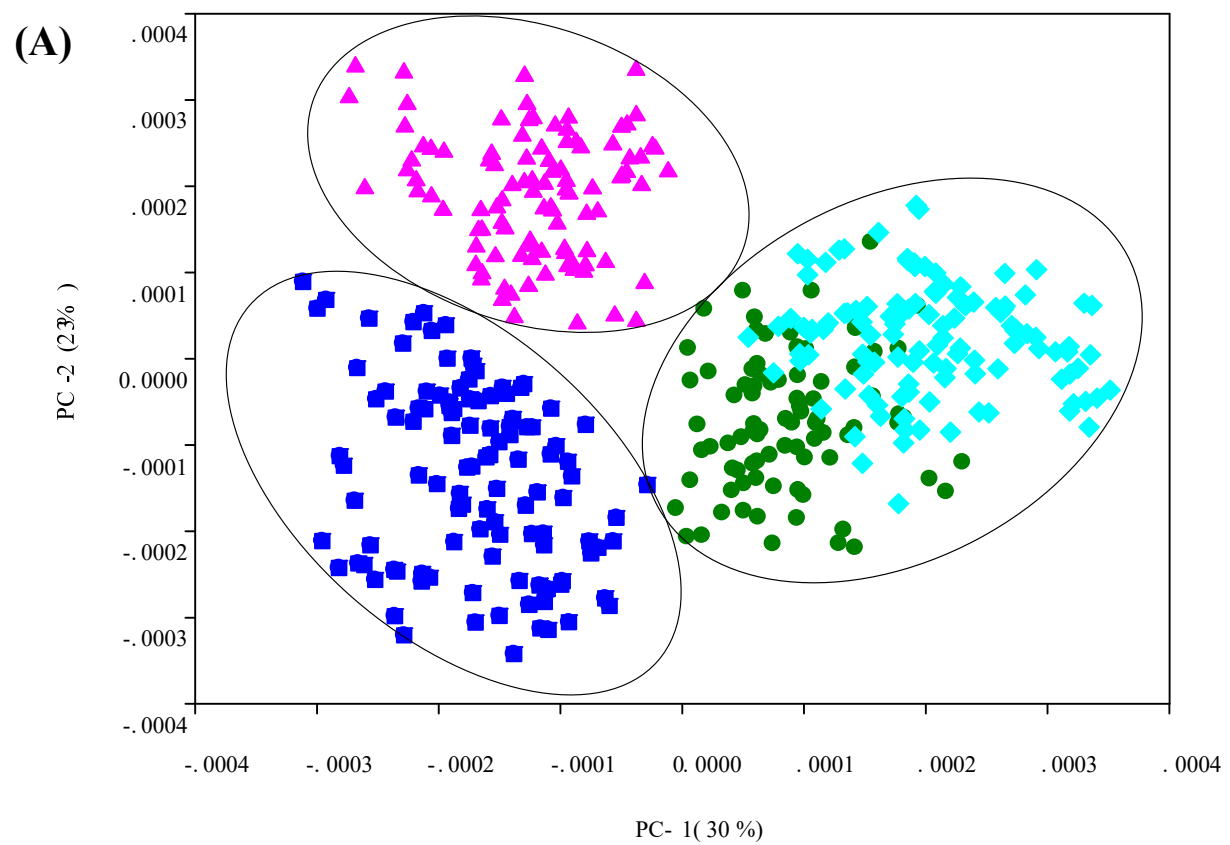

- $2 \% \mathrm{NaOH} \Delta 4 \% \mathrm{NaOH} \bullet 6 \% \mathrm{NaOH} \bullet 8 \% \mathrm{NaOH}$

(B)

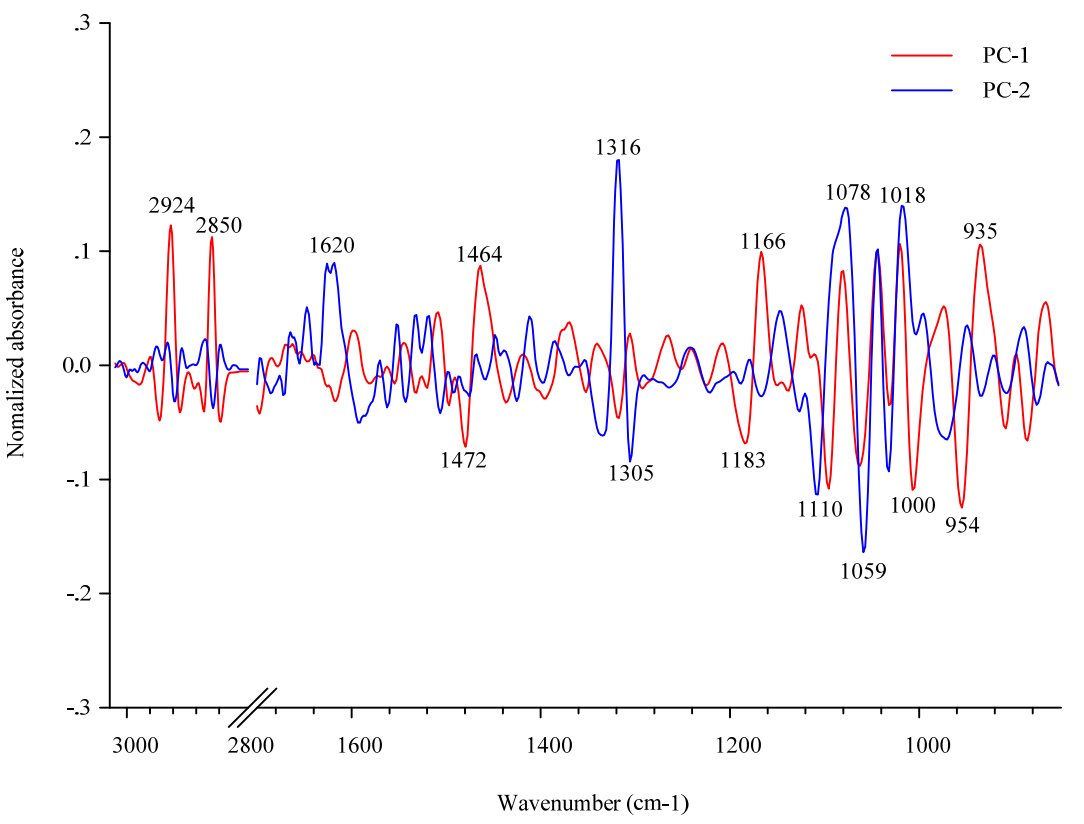

Figure 4. Principal component analysis (PCA) scores scatter plot of the Fourier transform infrared (FTIR) spectra of cassava distiller's dried grains extracted dietary fiber (DFCDG) treated with $\mathrm{NaOH}$ solution at concentrations $2 \%, 4 \%, 6 \%$, and $8 \%$, (A) PCA scores plot, (B) PCA loading plot.

\section{CONFLICT OF INTEREST}

We certify that there is no conflict of interest with any financial organization regarding the material discussed in the manuscript.

\section{FUNDING}

This work was supported by Suranaree University of Technology (SUT), Thailand Science Research and Innovation (TSRI), National Science, Research and Innovation Fund (NSRF), and the National Research Council of Thailand (NRCT) (SUT3-303-60-24-09).

The authors would like to acknowledge the staff of FTIR team (beam line 4.1: Infrared Spectroscopy and Imaging) from Synchrotron Light Research Institute (Public Organi- 
zation) in Thailand for their technical suggestions. We would also like to express our sincere thanks to Pascal Mermillod from Reproductive Physiology and Behavior unit, National Institute of Agronomical Research (INRA), France for his guiding and proofreading this manuscript with the support of the Siam Huber Curien grant $n^{\circ} 42879$ QC.

\section{REFERENCES}

1. Choct M. Feed non-starch polysaccharides for monogastric animals: classification and function. Anim Prod Sci 2015; 55:1360-6. https://doi.org/10.1071/AN15276

2. Knudsen KEB. Fiber and nonstarch polysaccharide content and variation in common crops used in broiler diets. Poult Sci 2014;93:2380-93. https://doi.org/10.3382/ps.2014-03902

3. Walugembe M, Hsieh JCF, Koszewski NJ, Lamont SJ, Persia ME, Rothschild MF. Effects of dietary fiber on cecal shortchain fatty acid and cecal microbiota of broiler and layinghen chicks. Poult Sci 2015;94:2351-9. https://doi.org/10. 3382/ps/pev242

4. Jha R, Mishra P. Dietary fiber in poultry nutrition and their effects on nutrient utilization, performance, gut health, and on the environment: a review. J Anim Sci Biotechnol 2021; 12:51. https://doi.org/10.1186/s40104-021-00576-0

5. Kosugi A, Kondo A, Ueda M, et al. Production of ethanol from cassava pulp via fermentation with a surface-engineered yeast strain displaying glucoamylase. Renew Energy 2009;34: 1354-8. https://doi.org/10.1016/j.renene.2008.09.002

6. Wan R, Zheng X, Chen Y, Wang H. Using cassava distiller's dried grains as carbon and microbe sources to enhance denitrification of nitrate-contaminated groundwater. Appl Microbiol Biotechnol 2015;99:2839-47. https://doi.org/10. 1007/s00253-014-6155-z

7. Zhang H, Wang H, Cao X, Wang J. Preparation and modification of high dietary fiber flour: a review. Food Res Int 2018;113:24-35. https://doi.org/10.1016/j.foodres.2018.06. 068

8. Daou C, Zhang H. Optimization of processing parameters for extraction of total, insoluble and soluble dietary fibers of defatted rice bran. Emirates J Food Agric 2013;25:562-75. https://doi.org/10.9755/ejfa.v25i8.14513

9. Samanta AK, Jayapal N, Jayaram C, et al. Xylooligosaccharides as prebiotics from agricultural by-products: Production and applications. Bioact Carbohydr Diet Fibre 2015;5:62-71. https://doi.org/10.1016/j.bcdf.2014.12.003

10. Abeysekara S, Damiran D, Yu P. Spectroscopic impact on protein and carbohydrate inherent molecular structures of barley, oat and corn combined with wheat DDGS. J Spectrosc 2011;26:671049. https://doi.org/10.3233/SPE-2011-0546

11.Chylińska M, Szymańska-Chargot M, Kruk B, Zdunek A. Study on dietary fibre by Fourier transform-infrared spectroscopy and chemometric methods. Food Chem 2016;196:
114-22. https://doi.org/10.1016/j.foodchem.2015.09.029

12.Pouzet M, Dubois M, Charlet K, Béakou A. The effect of lignin on the reactivity of natural fibres towards molecular fluorine. Mater Des 2017;120:66-74. https://doi.org/10.1016/ j.matdes.2017.01.086

13. Sacithraa R, MadhanMohan M, Vijayachitra S. Quantitative analysis of tapioca starch using FT-IR spectroscopy and partial least squares. Int J Comput Appl 2013;975:29-33.

14. Cerna M, Barros AS, Nunes A, et al. Use of FT-IR spectroscopy as a tool for the analysis of polysaccharide food additives. Carbohydr Polym 2003;51:383-9. https://doi.org/10.1016/ S0144-8617(02)00259-X

15. Fan M, Dai D, Huang B. Fourier transform infrared spectroscopy for natural fibres. In: Salih SM, editor. Fourier transformmaterials analysis. Rijeka, Croatia: InTech; 2012.

16. AOAC. Official methods of analysis. 15th edition, Association of Official Analytical Chemist, Washington, DC, USA: AOAC International; 1990.

17.Jarvis RM, Goodacre R. Genetic algorithm optimization for pre-processing and variable selection of spectroscopic data. Bioinformatics 2005;21:860-8. https://doi.org/10.1093/bio informatics/bti102

18.SPSS, Inc. U. IBM SPSS Modeler 18.0 User's guide. 2010. Chicago, IL, USA: SPSS Inc; 2010.

19. Dhingra D, Michael M, Rajput H, Patil RT. Dietary fibre in foods: a review. J Food Sci Technol 2012;49:255-66. https:// doi.org/10.1007/s13197-011-0365-5

20.Jayapal N, Samanta AK, Kolte AP, et al. Value addition to sugarcane bagasse: Xylan extraction and its process optimization for xylooligosaccharides production. Ind Crops Prod 2013;42:14-24. https://doi.org/10.1016/j.indcrop.2012.05.019

21. Harun S, Geok SK. Effect of sodium hydroxide pretreatment on rice straw composition. Indian J Sci Technol 2016;9:1-9. https://doi.org/10.17485/ijst/2016/v9i21/95245

22.Lammers K, Arbuckle-Keil G, Dighton J. FT-IR study of the changes in carbohydrate chemistry of three New Jersey pine barrens leaf litters during simulated control burning. Soil Biol Biochem 2009;41:340-7. https://doi.org/10.1016/j.soilbio. 2008.11.005

23. Corredor DY, Salazar JM, Hohn KL, Bean S, Bean B, Wang D. Evaluation and characterization of forage sorghum as feedstock for fermentable sugar production. Appl Biochem Biotechnol 2009;158:164. https://doi.org/10.1007/s12010-008-8340-y

24. McKee GA, Soong JL, Caldéron F, Borch T, Cotrufo MF. An integrated spectroscopic and wet chemical approach to investigate grass litter decomposition chemistry. Biogeochemistry 2016;128:107-23. https://doi.org/10.1007/s10533-016-0197-5

25.Uthumporn U, Zainun SN, Karim AA, Tajul AY. Extraction and characterization of non-starch polysaccharides from different growth stages of sago starch. Pakistan J Nutr 2014; 13:287-95.

26.Chirinang P, Oonsivilai R, Kulrattanarak T. Ultrasound 
assisted extraction for preparation dietary fiber from cassava pulp. Adv Mat Res 2014;931-932:1502-6. https://doi.org/10. 4028/www.scientific.net/AMR.931-932.1502

27. Abidi N, Cabrales L, Haigler CH. Changes in the cell wall and cellulose content of developing cotton fibers investigated by FTIR spectroscopy. Carbohydr Polym 2014;100:9-16. https://doi.org/10.1016/j.carbpol.2013.01.074

28. Ying D, Hlaing MM, Lerisson J, et al. Physical properties and FTIR analysis of rice-oat flour and maize-oat flour based extruded food products containing olive pomace. Food Res Int 2017;100:665-73. https://doi.org/10.1016/j.foodres.2017. 07.062

29. Cheikh Rouhou M, Abdelmoumen S, Thomas S, Attia H, Ghorbel D. Use of green chemistry methods in the extraction of dietary fibers from cactus rackets (Opuntia ficus indica): Structural and microstructural studies. Int J Biol Macromol 2018;116:901-10. https://doi.org/10.1016/j.ijbiomac.2018. 05.090 